\title{
The effect of the comorbidity burden on vitamin D levels in geriatric hip fracture
}

\author{
Ing How Moo ${ }^{1 *}$ (D), Carmen Jia Wen Kam², Eric Wei Liang Cher ${ }^{1}$, Bryan Ce Jie Peh ${ }^{1}$, Chung Ean Lo', \\ David Thai Chong Chua ${ }^{2}$, Ngai Nung Lo' ${ }^{1}$ Tet Sen Howe ${ }^{1}$ and Joyce Suang Bee Koh ${ }^{1}$
}

\begin{abstract}
Background: Elderly patients with hip fractures often have multiple medical comorbidities, and vitamin D deficiency is common in this population. Accumulating evidence links low vitamin D levels to various comorbidities. However, very little is known about the collective impact of comorbidities on vitamin D levels. The Charlson Comorbidity Index $(\mathrm{CCl})$ is a validated comorbidity burden index. We hypothesized that a high $\mathrm{CCl}$ score is associated with vitamin D deficiency in elderly patients with hip fracture.

Methods: A retrospective cohort study was conducted among all hospitalized elderly patients aged $>60$ years admitted for low-energy hip fracture in a single tertiary hospital from 2013 to 2015. Data regarding patient demographics, fracture type, serum 25-hydroxyvitamin D3 levels and age-adjusted CCI score were collected and analysed.
\end{abstract}

Results: Of the 796 patients included in the study, 70.6\% $(n=562)$ of the patients were women and the mean age was $77.7 \pm 8.0$ years. The mean vitamin D level was $20.4 \pm 7.4 \mathrm{ng} / \mathrm{mL}$, and $91.7 \%$ ofhospitalized elderly patients with hip fracture had inadequate vitamin D level. There was no correlation between the individual serum vitamin $D$ level with respect to age-adjusted $\mathrm{CCl}$ (Pearson correlation coefficient $=0.01 ; p=0.87$ ). After stratifying the $\mathrm{CCl}$ scores into low and high comorbidity burden groups (i.e., with scores $1-2$ and $\geq 3$ ), there was no relationship between the 2 subgroups for age-adjusted $\mathrm{CCl}$ and vitamin D levels $(p=0.497)$. Furthermore, there was also no association among age, gender, fracture type, and smoking status with the mean 25(OH)D level $(p>0.05)$.

Conclusion: Low vitamin D levels were highly prevalent in our hip fracture cohort. There was no relationship between the $\mathrm{CCl}$ score and vitamin D levels in the geriatric hip population. The comorbidity burden in geriatric patients with hip fractures did not seem to be a significant factor for vitamin D levels.

Keywords: Vitamin D, Charlson comorbidity index, Hip fracture

\section{Background}

Hip fracture often results in substantial morbidity, loss of independence, and mortality among the elderly population. Elderly patients with hip fractures often have multiple medical comorbidities, and only $4.9 \%$ of the elderly population with hip fracture patients reported no

\footnotetext{
* Correspondence: zell53@hotmail.com

'Department of Orthopedic Surgery, Singapore General Hospital, Singapore, Singapore

Full list of author information is available at the end of the article
}

comorbidity [1]. Vitamin D deficiency is also highly prevalent among this population, ranging from 55 to 96.7\% [2-4]. Even in the tropical country of Singapore, vitamin D deficiency was previously reported to be highly prevalent among hip fracture cohorts [5]. The high prevalence of vitamin D deficiency in elderly patients with multiple comorbidities that had hip fractures might not be just a coincidence.

Vitamin D deficiency contributes to increased fracture risk in the elderly population $[4,6,7]$. Suboptimal

(c) The Author(s). 2020 Open Access This article is licensed under a Creative Commons Attribution 4.0 International License, which permits use, sharing, adaptation, distribution and reproduction in any medium or format, as long as you give appropriate credit to the original author(s) and the source, provide a link to the Creative Commons licence, and indicate if changes were made. The images or other third party material in this article are included in the article's Creative Commons licence, unless indicated otherwise in a credit line to the material. If material is not included in the article's Creative Commons licence and your intended use is not permitted by statutory regulation or exceeds the permitted use, you will need to obtain permission directly from the copyright holder. To view a copy of this licence, visit http://creativecommons.org/licenses/by/4.0/. The Creative Commons Public Domain Dedication waiver (http://creativecommons.org/publicdomain/zero/1.0/) applies to the data made available in this article, unless otherwise stated in a credit line to the data. 
vitamin D levels are associated with impaired muscle strength and increased fall risks. It can also cause high bone turnover and low bone mineral density. In addition to its traditional effects on bone and mineral metabolism, accumulating evidence linking low vitamin $\mathrm{D}$ to various comorbidities involving nearly all organ systems as the vitamin $\mathrm{D}$ receptor has been found in many tissues outside the skeletal system [8-16].

Several investigations have reported a relationship between individual comorbidities and vitamin $\mathrm{D}$ deficiency $[7,9,12-15,17-21]$. However, very little is known about the collective impact of comorbidities on vitamin $\mathrm{D}$ levels. The Charlson Comorbidity Index $(\mathrm{CCI})$ is the most widely used method of assessing a patient's overall comorbidity burden in clinical research [22]. The higher the score, the more severe the burden of comorbidity. Higher CCI scores have been shown to be associated with increased mortalities, length of stay and readmission in the geriatric hip fracture population [23-25].

To the best of our knowledge, no study has assessed the correlation of CCI with vitamin D deficiency. The purpose of this study was to use data from a large, level 1 trauma centre to explore the relationship between the CCI score and vitamin D deficiency. We hypothesized that a high CCI score is associated with low vitamin D levels in elderly patients with hip fractures.

\section{Materials and methods}

This study (CIRB Ref: 2015/2134) was approved by the Singhealth Centralized Institutional Review Board, Singapore. We retrospectively studied data collected from January 2013 to December 2015 at a single tertiary hospital. The inclusion criteria were patients of aged > 60 years with femoral neck, intertrochanteric, or subtrochanteric fractures after a low-energy fall. The exclusion criteria were patients of age $<60$ years, high-impact injuries, periprosthetic, peri-implant, pathological, and atypical femoral fractures. A retrospective review of the electronic medical records database was conducted for each patient. Data on patient demographics, including age, ethnicity, medical comorbidities, fracture type, CCI and serum 25-hydroxyvitamin $\mathrm{D}_{3}[25(\mathrm{OH}) \mathrm{D}]$ levels, were collected and analysed.

All patients were assessed using the age-adjusted CCI, calculated based on 17 comorbid conditions, with each assigned a weight of 1 to 6 . The age-adjusted CCI takes into account each decade after 50 years of age as one point [26]. Based on the CCI score, the severity of comorbidity burden is usually classified into three grades: mild (CCI score 1-2), moderate (CCI score 3-4) and severe (CCI score $\geq 5$ ). Accordingly, we considered the comorbidity burden as high grade if the CCI score was greater than or equal to 3 and low grade if the CCI score was less than 3.
The serum 25(OH)D levels were measured immediately upon admission using the radioimmunoassay method as part of the institution hip fracture protocol. In contrast to 1,25-dihydroxyitamin $\mathrm{D}$, the serum $25(\mathrm{OH}) \mathrm{D}$ level is the best indicator of total vitamin $\mathrm{D}$ status, as it has a long half-life of 15 days and reflects the net incoming contributions from cutaneous synthesis and total dietary intake [27]. The serum vitamin D level was further categorized according to Holick's classification, where vitamin deficiency is defined as a vitamin D level $<20 \mathrm{ng} / \mathrm{mL}$, vitamin D insufficiency as a vitamin D level $21-29 \mathrm{ng} / \mathrm{mL}$, and normal vitamin D levels are $\geq 30$ $\mathrm{ng} / \mathrm{mL}[7,8]$.

\section{Statistical analysis}

Statistical analysis was performed by a statistician using SPSS statistical software, version 19.0 (IBM Corp. Armonk, NY). Numerical data are presented as the mean and standard deviation, while categorical data are presented as frequency and percentage. The analysis sample was stratified into different groups by age, gender, smoking history, age-adjusted CCI, and individual comorbidities of the CCI. The mean levels of serum vitamin D were computed for each group. Comparisons within each group were performed using a 2-tailed $t$-test or one-way ANOVA. Pearson's correlation coefficient was used to find the correlation between individual vitamin D levels and CCI. A two-tailed $p$-value of $<0.05$ was considered statistically significant.

\section{Results}

Of the 1087 patients with hip fracture admitted during the period from January 2013 to December 2015, 92\% ( $n=1002$ patients) met the inclusion criteria. Data on vitamin D levels were available in $80 \%$ of the included patients ( $n=796$ patients) and were used in the analysis. Of the 796 patients included in the study, 562 (70.6\%) were female. The mean age of the study population was $77.7 \pm 8.0$ years, and $83.6 \%$ of the patients were aged $\geq 70$ years. The majority of the patients had femoral neck fractures $(60.7 \%)$.

The mean vitamin D level of our study population was $20.4 \pm 7.4 \mathrm{ng} / \mathrm{mL}$. The prevalence of vitamin D deficiency among hospitalized elderly patients with hip fracture was $53.9 \%(n=429)$, and vitamin $\mathrm{D}$ insufficiency was present in $37.8 \%$ of the patients $(n=301)$. Only $8.3 \%$ of all patients had normal vitamin D levels. Although there was no difference in vitamin $\mathrm{D}$ levels between Chinese and Malay patients, Indian patients had significantly lower vitamin D levels than the Chinese patients. Patient characteristics, demographic data, and distribution of $25(\mathrm{OH}) \mathrm{D}$ are summarized in Table 1.

The mean age-adjusted CCI was $4.5 \pm 1.8$ years. The distribution of age-adjusted $\mathrm{CCI}$ with its corresponding mean 
Table 1 Patient characteristics, demographic data, and distribution of vitamin D levels

\begin{tabular}{|c|c|c|c|c|}
\hline Variables & $\boldsymbol{n}=796$ & $\%$ & 25(OH)D, ng/ml (mean $\pm \mathrm{SD})$ & $\boldsymbol{p}$-value \\
\hline \multicolumn{5}{|l|}{ Age (mean) } \\
\hline $60-69$ & 131 & 16.5 & $20.0 \pm 8.1$ & \multirow[t]{4}{*}{0.854} \\
\hline 70-79 & 326 & 41.0 & $20.5 \pm 6.8$ & \\
\hline $80-89$ & 287 & 36.1 & $20.7 \pm 7.6$ & \\
\hline$\geq 90$ & 52 & 6.5 & $20.1 \pm 8.0$ & \\
\hline \multicolumn{5}{|l|}{ Gender } \\
\hline Female & 562 & 70.6 & $20.3 \pm 7.5$ & \multirow[t]{2}{*}{0.615} \\
\hline Male & 234 & 29.4 & $20.6 \pm 7.0$ & \\
\hline \multicolumn{5}{|l|}{ Race } \\
\hline Chinese & 702 & 88.2 & $20.7 \pm 7.1^{*}$ & \multirow[t]{4}{*}{0.012} \\
\hline Malay & 54 & 6.8 & $18.8 \pm 8.4$ & \\
\hline Indian & 32 & 4.0 & $16.6 \pm 8.1^{*}$ & \\
\hline Others & 8 & 1.0 & $22.0 \pm 14.0$ & \\
\hline \multicolumn{5}{|l|}{ Current smoker } \\
\hline No & 709 & 89.1 & $20.4 \pm 7.5$ & \multirow[t]{2}{*}{0.884} \\
\hline Yes & 87 & 10.9 & $20.3 \pm 6.4$ & \\
\hline \multicolumn{5}{|l|}{ Type of fracture } \\
\hline Neck of femur & 483 & 60.7 & $20.4 \pm 7.3$ & \multirow[t]{3}{*}{0.485} \\
\hline Intertrochanteric & 303 & 38.1 & $20.3 \pm 7.5$ & \\
\hline Subtrochancteric & 10 & 1.3 & $23.2 \pm 7.3$ & \\
\hline
\end{tabular}

*Bonferroni's posthoc correction showed that the significant difference of Vitamin D level was between Chinese and Indian ( $p=0.012)$

vitamin D level is shown in Table 2. There was no correlation between the serum vitamin $\mathrm{D}$ level and the ageadjusted CCI (Pearson's correlation coefficient $=0.003$, $p=0.938$ ) (Fig. 1). Approximately $7.8 \%$ of the patients with low comorbidity burden had a mean $25(\mathrm{OH}) \mathrm{D}$ level of $20.1 \pm 7.2 \mathrm{ng} / \mathrm{mL}$, and the remaining $92.2 \%$ of the patients with high comorbidity burden had a mean $25(\mathrm{OH}) \mathrm{D}$ level of $20.5 \pm 7.4$. After stratifying the CCI scores into these 2 groups, we did not find significant differences between the 2 subgroups for age-adjusted CCI and 25(OH)D levels ( $p=0.497)$ (Fig. 2). Moreover, there was no association among age, gender and fracture types with the mean vitamin $\mathrm{D}$ level $(p>0.05)$. Of all the comorbidities in the geriatric hip fracture population, diabetes mellitus (DM) was the most prevalent comorbid condition $(25.1 \%)$, followed by cerebrovascular accident (14.8\%) and chronic renal disease (9.9\%). Patients with DM with end-organ damage, chronic kidney disease, and congestive heart failure were found to have lower vitamin $\mathrm{D}$ levels $(p<0.05)$. In contrast, patients with dementia and cancer had significantly higher vitamin D levels $(p<0.05)$.

\section{Discussion}

Our study findings suggested that virtually all elderly patients with hip fracture had low vitamin D levels. Only $8.3 \%$ of our patients had normal vitamin $\mathrm{D}$ levels. The high prevalence of $25(\mathrm{OH}) \mathrm{D}$ deficiency noted in our study was similar to other reports on elderly with hip fractures $[4,7,28,29]$. The vitamin D level appeared unaffected by age, gender, and smoking status in our cohort, but it was significantly lower among Indian patients. This could have genetic or dietary implications and deserves further research.

Since the medical conditions associated with $25(\mathrm{OH}) \mathrm{D}$ deficiency are represented in the CCI and nearly all geriatric patients with osteoporotic hip fractures have multiple comorbidities, it would be logical to expect that patients with a higher comorbidity burden would be associated with a lower vitamin D level, i.e., a high CCI score correlated with a lower $25(\mathrm{OH}) \mathrm{D}$ level. Our study did not find any correlation between the vitamin $\mathrm{D}$ level and CCI scores in the elderly hip fracture population. To the best of our knowledge, this was the first study to analyse the relationship between CCI and vitamin D levels.

Vitamin D has gained much interest recently with the revelation of its role far beyond bone metabolism. Many studies have reported associations between suboptimal vitamin D levels and various comorbidities, including [1] cancers of the prostate, colon, pancreas, ovary, stomach, and breast [2]; cardiovascular diseases, including hypertension, myocardial infarction, and congestive heart failure [3]; diabetes mellitus [4]; infectious diseases, including HIV [5]; autoimmune 
Table 2 The mean vitamin D level based on the Charlson Comorbidity Index and the individual comorbidities

\begin{tabular}{|c|c|c|c|c|}
\hline Variables & $\boldsymbol{n}=796$ & $\%$ & 25(OH)D, ng/ml (mean $\pm \mathrm{SD})$ & $\boldsymbol{p}$-value \\
\hline \multicolumn{5}{|c|}{ Age-adjusted CCl } \\
\hline $1-2$ & 62 & 7.8 & $20.1 \pm 7.2$ & \multirow{4}{*}{0.971} \\
\hline $3-4$ & 377 & 47.4 & $20.4 \pm 6.9$ & \\
\hline $5-6$ & 257 & 32.3 & $20.5 \pm 7.2$ & \\
\hline$\geq 7$ & 100 & 12.6 & $20.5 \pm 9.6$ & \\
\hline \multicolumn{5}{|l|}{ DM } \\
\hline No & 596 & 74.9 & $20.4 \pm 7.1$ & \multirow[t]{2}{*}{0.973} \\
\hline Yes & 200 & 25.1 & $20.4 \pm 8.1$ & \\
\hline \multicolumn{5}{|c|}{ DM with end organ damage } \\
\hline No & 790 & 99.2 & $20.5 \pm 7.4$ & \multirow[t]{2}{*}{0.009} \\
\hline Yes & 6 & 0.8 & $12.6 \pm 5.0$ & \\
\hline \multicolumn{5}{|c|}{ Myocardial infarction } \\
\hline No & 771 & 96.9 & $20.5 \pm 7.3$ & \multirow[t]{2}{*}{0.208} \\
\hline Yes & 25 & 3.1 & $18.6 \pm 9.3$ & \\
\hline \multicolumn{5}{|c|}{ Congestive cardiac failure } \\
\hline No & 767 & 96.4 & $20.6 \pm 7.3$ & \multirow[t]{2}{*}{0.015} \\
\hline Yes & 29 & 3.6 & $17.1 \pm 7.7$ & \\
\hline \multicolumn{5}{|c|}{ Cerebrovascular accident } \\
\hline No & 678 & 85.2 & $20.3 \pm 7.4$ & \multirow[t]{2}{*}{0.388} \\
\hline Yes & 118 & 14.8 & $21.0 \pm 7.3$ & \\
\hline \multicolumn{5}{|c|}{ Hemiplegia } \\
\hline No & 768 & 96.5 & $20.4 \pm 7.3$ & \multirow[t]{2}{*}{0.920} \\
\hline Yes & 28 & 3.5 & $20.6 \pm 8.6$ & \\
\hline \multicolumn{5}{|l|}{ Dementia } \\
\hline No & 744 & 93.5 & $20.3 \pm 7.3$ & \multirow[t]{2}{*}{0.010} \\
\hline Yes & 52 & 6.5 & $23.0 \pm 7.9$ & \\
\hline \multicolumn{5}{|l|}{ COPD } \\
\hline No & 778 & 97.7 & $20.5 \pm 7.4$ & \multirow[t]{2}{*}{0.197} \\
\hline Yes & 18 & 2.3 & $18.2 \pm 7.6$ & \\
\hline \multicolumn{5}{|c|}{ Connective tissue disease } \\
\hline No & 100 & 100.0 & $20.4 \pm 7.4$ & \multirow[t]{2}{*}{-} \\
\hline Yes & 0 & 0.0 & - & \\
\hline \multicolumn{5}{|l|}{ PUD } \\
\hline No & 762 & 95.7 & $20.4 \pm 7.4$ & \multirow[t]{2}{*}{0.710} \\
\hline Yes & 34 & 4.3 & $20.9 \pm 7.9$ & \\
\hline \multicolumn{5}{|c|}{ Chronic kidney disease } \\
\hline No & 717 & 90.1 & $20.7 \pm 7.2$ & \multirow[t]{2}{*}{0.016} \\
\hline Yes & 79 & 9.9 & $18.1 \pm 8.9$ & \\
\hline Peripheral & & & & \\
\hline No & 783 & 98.4 & $20.4 \pm 7.3$ & 0.605 \\
\hline Yes & 13 & 1.6 & $19.4 \pm 9.4$ & \\
\hline Cancer & & & & \\
\hline No & 743 & 93.3 & $20.2 \pm 7.2$ & 0.001 \\
\hline Yes & 53 & 6.7 & $23.7 \pm 8.8$ & \\
\hline
\end{tabular}


Table 2 The mean vitamin D level based on the Charlson Comorbidity Index and the individual comorbidities (Continued)

\begin{tabular}{|c|c|c|c|c|}
\hline Variables & $\boldsymbol{n}=796$ & $\%$ & 25(OH)D, ng/ml (mean $\pm \mathrm{SD})$ & $\boldsymbol{p}$-value \\
\hline \multicolumn{5}{|l|}{ Metastasis } \\
\hline No & 790 & 99.2 & $20.4 \pm 7.4$ & \multirow[t]{2}{*}{0.806} \\
\hline Yes & 6 & 0.8 & $21.2 \pm 7.5$ & \\
\hline \multicolumn{5}{|c|}{ Depression } \\
\hline No & 773 & 97.1 & $20.4 \pm 7.3$ & \multirow[t]{2}{*}{0.751} \\
\hline Yes & 23 & 2.9 & $21.1 \pm 10.2$ & \\
\hline \multicolumn{5}{|l|}{ Warfarin } \\
\hline No & 787 & 98.9 & $20.4 \pm 7.4$ & \multirow[t]{2}{*}{0.837} \\
\hline Yes & 9 & 1.1 & $20.9 \pm 5.4$ & \\
\hline \multicolumn{5}{|l|}{ Mild liver } \\
\hline No & 783 & 98.4 & $20.5 \pm 7.4$ & \multirow[t]{2}{*}{0.188} \\
\hline Yes & 13 & 1.6 & $17.8 \pm 7.1$ & \\
\hline \multicolumn{5}{|c|}{ Severe liver } \\
\hline No & 790 & 99.2 & $20.4 \pm 7.3$ & \multirow[t]{2}{*}{0.717} \\
\hline Yes & 6 & 0.8 & $22.8 \pm 15.1$ & \\
\hline \multicolumn{5}{|l|}{ AIDS } \\
\hline No & 794 & 99.7 & $20.4 \pm 7.4$ & \multirow[t]{2}{*}{0.139} \\
\hline Yes & 2 & 0.3 & $28.2 \pm 12.5$ & \\
\hline
\end{tabular}

Abbreviations: CCI Charlson Comorbidity Index, DM diabetes mellitus, COPD chronic obstructive pulmonary disease, PUD peptic ulcer disease, AIDS acquired immunodeficiency syndrome

diseases such as rheumatoid arthritis, Crohn's disease, and multiple sclerosis [6]; stroke [7]; chronic obstructive pulmonary diseases; and [8] mental health issues [7, 9, 12-15, 17-21].

When the comorbidities were bundled and represented collectively as $\mathrm{CCI}$, the association appears to be negated. The mean $25(\mathrm{OH}) \mathrm{D}$ level was $20.4 \pm 7.4$ $\mathrm{ng} / \mathrm{mL}$. We observed similar low vitamin D levels across all levels of CCI (Table 2). In other words, vitamin $\mathrm{D}$ deficiency is highly prevalent in the geriatric population with hip fracture, regulardless of the number of comorbidities. Hence, elderly patients with

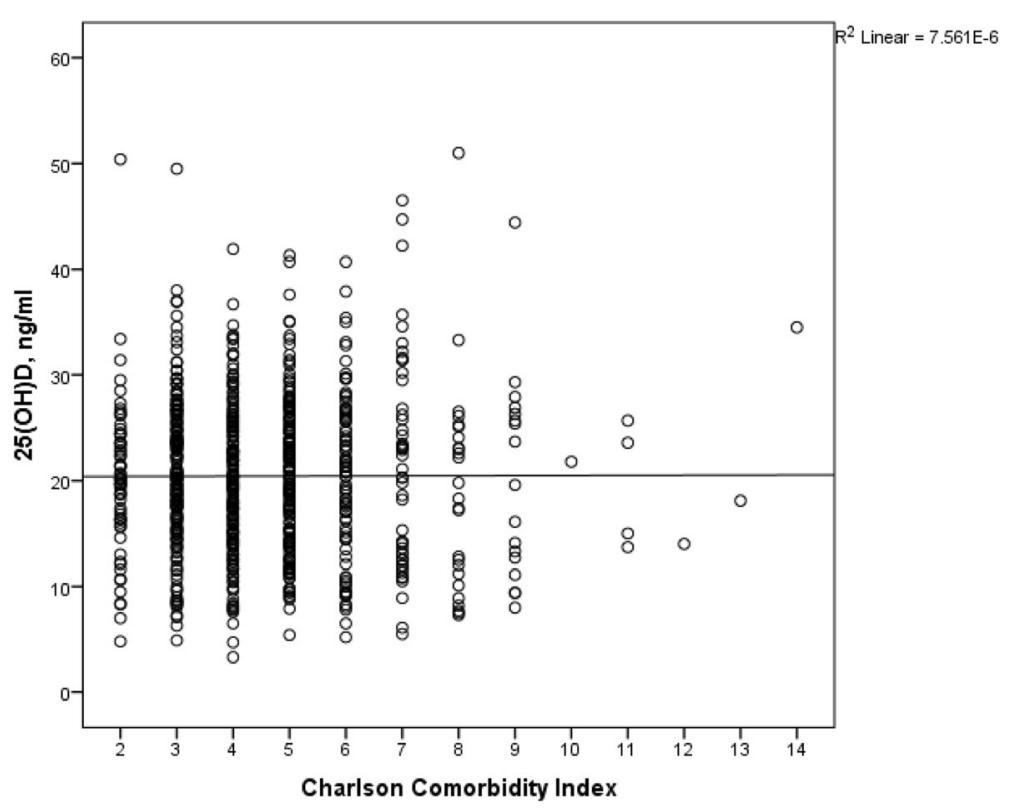

Fig. 1 Scatter plot demonstrating the distribution of serum vitamin D level with respect to the Charlson Comorbidity Index 


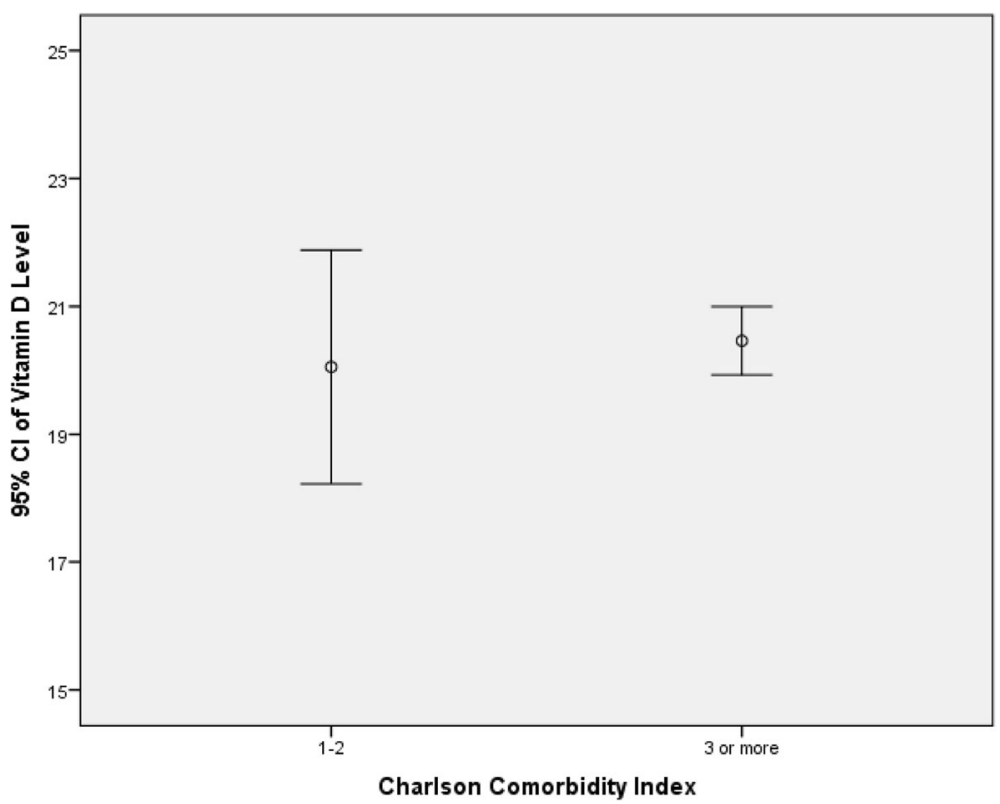

Fig. 2 Error plot illustrating the distribution of mean vitamin D levels stratified by comorbidity burden

more comorbidities might not be associated with lower vitamin D level.

There are certain limitations that should be accounted for in this retrospective database study. Data on vitamin D levels were not available for $20 \%$ of the patients that were admitted for hip fracture. We did not have details that may have influenced the serum 25(OH)D status, such as medication details, physical activity and sun exposure. In addition, a single vitamin $\mathrm{D}$ level measurement may be an imperfect surrogate as a long-term indicator of the vitamin D levels. However, Singapore is extremely close to the equator and has uniform temperature and abundant sunshine throughout the year. This climatic condition minimizes the seasonal variation in circulating vitamin D level compared to that in countries distal from the equator, which has substantially varying vitamin $D$ levels throughout the year, according to the season, in a nonlinear manner [3]. Although our study sample was large and represented the typical geriatric patient with hip fractures admitted to a hospital for treatment, our results cannot be extrapolated to other population groups [17]. The CCI might not be adequately sensitive to quantify the overall comorbidity burden in the geriatric hip fracture population. As the CCI is a composite index, it does not discriminate well among diseases and is not reflective of the severity of illness. Notably, the weight assigned to the individual comorbid conditions in $\mathrm{CCI}$ may not reflect their relative importance on the vitamin $\mathrm{D}$ level. One other possible explanation is that some of the associated conditions, such as inflammatory bowel diseases, are not part of the CCI score. Moreover, CCI includes some comorbidities that have no reported association with the vitamin D status, such as peptic ulcer disease, warfarin use, leukemia, lymphoma, metastasis, and several other solid cancers. The current literature seems to present more controversies than definitive conclusions with regard to the association of Vitamin D deficiency with various diseases and the role of vitamin $\mathrm{D}$ supplementation in preventive efforts. The level of $25(\mathrm{OH}) \mathrm{D}$ defined as vitamin $\mathrm{D}$ deficiency, remains controversial, and there is no consensus on the optimal level of $25(\mathrm{OH}) \mathrm{D}[30,31$ ]. Studies linking vitamin D status with the non-skeletal end-points arise from small observational case-control or cross-sectional experiments. The nature of the study design resulted in the identification of association and cannot prove a causal relationship [19]. The results from 34 intervention studies on vitamin $\mathrm{D}$ deficiency did not prove whether vitamin D supplementation is effective in reducing disease occurrence [32]. Recent large-scale studies continue to disprove the value of vitamin $\mathrm{D}$ supplementation in fracture prevention in community-dwelling older adults, cardiovascular protection, cancer prevention and diabetes [33-35]. The discrepancy between observational and interventional studies suggests that low vitamin D levels may only serve as a marker of ill health and are unlikely to be involved in the pathogenesis of diseases. Overall, the existing literature provides limited and conflicting support for any association between $25(\mathrm{OH}) \mathrm{D}$ status and non-skeletal health outcomes, and our current finding of a lack of association 
between CCI score and vitamin D levels would further underscore this issue.

In our study, DM with end-stage organ disease was significantly associated with lower vitamin D levels. There was no correlation between DM and vitamin D levels. Studies that examined the relationship between DM and vitamin D have reported inconsistent results. The association reported in some of these studies was limited to obese subjects, specific sex, and extremely low vitamin D levels [36, 37]. Consistent with some studies, we also observed lower vitamin D levels in patients with CCF [11]. Vitamin D is involved in multiple pathophysiological pathways relevant to heart failure. Data from large cohort studies have confirmed the association between vitamin D deficiency and the risk of CCF. However, other studies have not found any such association [38]. Vitamin D supplementation did not confer cardiovascular protection in a recent trial by Barbarawi et al. [39]. However, data from prospective clinical trials are lacking, and vitamin D supplementation does not decrease the risk of CCF and DM [12]. Dementia and cancer had significantly higher vitamin $\mathrm{D}$ levels in our study. This may be attributed to the routine vitamin D supplementation prescribed by the geriatricians and oncologists.

\section{Conclusions}

Low vitamin D levels were highly prevalent in our fragility hip fracture cohort and were associated with ethnicity (Indian race). However, we found no relationship between the CCI scores and vitamin D levels in the geriatric hip population. Although there was some association between low vitamin D levels and specific disease conditions, the overall comorbid burden of patients with hip fractures did not seem to be a significant factor for low vitamin D levels.

\section{Abbreviations}

CCl: Charlson Comorbidity Index; 25(OH)D: 25-hydroxyvitamin D3; DM: Diabetes mellitus; COPD: Chronic obstructive pulmonary disease; PUD: Peptic ulcer disease; AIDS: Acquired immunodeficiency syndrome

\section{Acknowledgements}

Not applicable.

\section{Authors' contributions}

$\mathrm{IH}$ designed the study, analysed and interpreted the data and was the major contributor in writing the manuscript. CJW analysed and interpreted the data. EWL, BCJ and CE contributed to the data acquisition and drafting of the manuscript. DTC, NN, TS and JSB designed the study, interpreted the data and substantively revised the manuscript. All authors read and approved the final manuscript.

\section{Funding}

None of the authors received any outside funding or grants in support of their research for preparation of this work.

\section{Availability of data and materials}

The datasets used and/or analysed during the current study are available from the corresponding author upon reasonable request.
Ethics approval and consent to participate

Centralized Institutional Review Board of SingHealth (CRIB: 2015/2134). The requirement for informed consent was waived.

\section{Consent for publication}

Not applicable.

\section{Competing interests}

The authors declare that they have no competing interests.

\section{Author details}

${ }^{1}$ Department of Orthopedic Surgery, Singapore General Hospital, Singapore, Singapore. ${ }^{2}$ Changi General Hospital, Singapore, Singapore.

Received: 27 May 2020 Accepted: 31 July 2020

Published online: 08 August 2020

\section{References}

1. Jürisson M, Raag M, Kallikorm R, Lember M, Uusküla A. The impact of comorbidities on hip fracture mortality: a retrospective population-based cohort study. Arch Osteoporos. 2017;12(1):76.

2. Burge R, Dawson-Hughes B, Solomon DH, Wong JB, King A, Tosteson A Incidence and economic burden of osteoporosis-related fractures in the United States, 2005-2025. J Bone Miner Res. 2007:22(3):465-75.

3. Ramason R, Selvaganapathi N, Ismail NHB, Wong WC, Rajamoney GN, Chong MS. Prevalence of Vitamin D deficiency in patients with hip fracture seen in an Orthogeriatric Service in Sunny Singapore. Geriatr Orthop Surg Rehabil. 2014:5(2):82-6.

4. Khadgawat R, Brar KS, Brar KS, Gahlo M, Yadav CS, Malhotra R, et al. High prevalence of vitamin D deficiency in Asian-Indian patients with fragility hip fracture: a pilot study. J Assoc Physicians India. 2010;58:539-42.

5. Chandran M, Howe T, Goh S, Li H, Ng A, Zhang R, Koh J. Vitamin D Levels, Physical and Biochemical Characteristics of South East Asian Patients with Osteoporotic Hip Fractures. J ASEAN Fed Endocr Soc. 2014;27(2).

6. Mezquita-Raya P, Muñoz-Torres M, Luna JD, Luna V, Lopez-Rodriguez F, Torres-Vela E, et al. Relation between vitamin D insufficiency, bone density, and bone metabolism in healthy postmenopausal women. J Bone Miner Res. 2001;16(8):1408-15

7. Holick MF. Vitamin D deficiency. N Engl J Med. 2007;357(3):266-81.

8. Holick MF, Binkley NC, Bischoff-Ferrari HA, Gordon CM, Hanley DA, Heaney $\mathrm{RP}$, et al. Evaluation, treatment, and prevention of vitamin D deficiency: an Endocrine Society clinical practice guideline. J Clin Endocrinol Metab. 2011; 96(7):1911-30

9. Merlino LA, Curtis J, Mikuls TR, Cerhan JR, Criswell LA, Saag KG. Vitamin D intake is inversely associated with rheumatoid arthritis: results from the lowa Women's health study. Arthritis Rheum. 2004:50(1):72-7.

10. Zittermann A. Vitamin D and disease prevention with special reference to cardiovascular disease. Prog Biophys Mol Biol. 2006;92(1):39-48.

11. Zittermann A, Schleithoff SS, Tenderich G, Berthold HK, Körfer R, Stehle P. Low vitamin D status: a contributing factor in the pathogenesis of congestive heart failure? J Am Coll Cardiol. 2003;41(1):105-12.

12. Ekmekcioglu C, Haluza D, Kundi M. 25-Hydroxyvitamin D Status and Risk for Colorectal Cancer and Type 2 Diabetes Mellitus: A Systematic Review and Meta-Analysis of Epidemiological Studies. Int J Environ Res Public Health. 2017;14(2).

13. Choi C, Seo M, Choi W, Kim K, Youn S, Lindsey T, et al. Relationship between serum 25-hydroxyvitamin D and lung function among Korean adults in Korea National Health and nutrition examination survey (KNHA NES), 2008-2010. J Clin Endocrinol Metab. 2013;98(4):1703-10.

14. Moretti R, Morelli ME, Caruso P. Vitamin D in Neurological Diseases: A Rationale for a Pathogenic Impact. Int J Mol Sci. 2018;19(8).

15. Iruzubieta P, Terán Á, Crespo J, Fábrega E. Vitamin D deficiency in chronic liver disease. World J Hepatol. 2014;6(12):901-15.

16. Poole KES, Loveridge N, Barker PJ, Halsall DJ, Rose C, Reeve J, et al. Reduced vitamin D in acute stroke. Stroke. 2006;37(1):243-5

17. Martins D, Wolf M, Pan D, Zadshir A, Tareen N, Thadhani $R$, et al. Prevalence of cardiovascular risk factors and the serum levels of 25-hydroxyvitamin D in the United States: data from the Third National Health and Nutrition Examination Survey, Arch Intern Med. 2007;167(11):1159-65. 
18. Li G, Mbuagbaw L, Samaan Z, Falavigna M, Zhang S, Adachi JD, et al. Efficacy of Vitamin D supplementation in depression in adults: a systematic review. J Clin Endocrinol Metab. 2014;99(3):757-67.

19. Zhu M, Wang T, Wang C, Ji Y. The association between vitamin $D$ and COPD risk, severity, and exacerbation: an updated systematic review and meta-analysis. Int J Chron Obstruct Pulmon Dis. 2016;11:2597-607.

20. Hsieh E, Yin MT. Continued interest and controversy: Vitamin D in HIV. Curr HIV/AIDS Rep. 2018;15(3):199-211.

21. Sommer I, Griebler U, Kien C, Auer S, Klerings I, Hammer R, et al. Vitamin D deficiency as a risk factor for dementia: a systematic review and metaanalysis. BMC Geriatr. 2017;17(1):16.

22. Burgos E, Gómez-Arnau Jl, Díez R, Muñoz L, Fernández-Guisasola J. Garcia del Valle $S$. predictive value of six risk scores for outcome after surgical repair of hip fracture in elderly patients. Acta Anaesthesiol Scand. 2008:52(1):125-31.

23. González-Zabaleta J, Pita-Fernandez S, Seoane-Pillado T, López-Calviño B, Gonzalez-Zabaleta JL. Comorbidity as a predictor of mortality and mobility after hip fracture. Geriatr Gerontol Int. 2016;16(5):561-9.

24. Johnson DJ, Greenberg SE, Sathiyakumar V, Thakore R, Ehrenfeld JM, Obremskey WT, et al. Relationship between the Charlson comorbidity index and cost of treating hip fractures: implications for bundled payment. J Orthop Traumatol. 2015;16(3):209-13.

25. Lakomkin N, Kothari P, Dodd AC, VanHouten JP, Yarlagadda M, Collinge CA, et al. Higher Charlson comorbidity index scores are associated with increased hospital length of stay after lower extremity Orthopaedic trauma. J Orthop Trauma. 2017;31(1):21-6.

26. Charlson M, Szatrowski TP, Peterson J, Gold J. Validation of a combined comorbidity index. J Clin Epidemiol. 1994;47(11):1245-51.

27. Leino A, Turpeinen U, Koskinen P. Automated measurement of $25-\mathrm{OH}$ vitamin D3 on the Roche modular E170 analyzer. Clin Chem. 2008;54(12):2059-62.

28. Avenell A, Mak JCS, O'Connell D. Vitamin D and vitamin D analogues for preventing fractures in post-menopausal women and older men. Cochrane Database Syst Rev. 2014;4:CD000227.

29. Cauley JA, Lacroix AZ, Wu L, Horwitz M, Danielson ME, Bauer DC, et al. Serum 25-hydroxyvitamin D concentrations and risk for hip fractures. Ann Intern Med. 2008;149(4):242-50.

30. Palacios C, Gonzalez L. Is vitamin D deficiency a major global public health problem? J Steroid Biochem Mol Biol. 2014:144:138-45.

31. Bischoff-Ferrari HA. Optimal serum 25-hydroxyvitamin D levels for multiple health outcomes. Adv Exp Med Biol. 2014;810:500-25.

32. Autier P, Boniol M, Pizot C, Mullie P. Vitamin D status and ill health: a systematic review. Lancet Diabetes Endocrinol. 2014;2(1):76-89.

33. Pittas AG, Dawson-Hughes B, Sheehan P, Ware JH, Knowler WC, Aroda VR, et al. Vitamin D Supplementation and Prevention of Type 2 Diabetes. N Engl J Med. 2019;381(6):520-30.

34. Zhao J, Zeng X, Wang J, Liu L. Association Between Calcium or Vitamin D Supplementation and Fracture Incidence in Community-Dwelling Older Adults. JAMA. 2017;318(24):2466-82.

35. Manson JE, Cook NR, Lee I, Christen W, Bassuk SS, Mora S, et al. Vitamin D Supplements and Prevention of Cancer and Cardiovascular Disease. N Engl J Med. 2019:380(1):33-44.

36. Park SK, Garland CF, Gorham ED, BuDoff L, Barrett-Connor E. Plasma 25hydroxyvitamin $\mathrm{D}$ concentration and risk of type 2 diabetes and prediabetes: 12-year cohort study. PLoS One. 2018;13(4):e0193070.

37. Mitri J, Muraru MD, Pittas AG. Vitamin D and type 2 diabetes: a systematic review. Eur J Clin Nutr. 2011;65(9):1005-15.

38. Marshall Brinkley D, Ali OM, Zalawadiya SK, Wang TJ. Vitamin D and Heart Failure. Curr Heart Fail Rep. 2017;14(5):410-20.

39. Barbarawi M, Kheiri B, Zayed Y, Barbarawi O, Dhillon H, Swaid B, et al. Vitamin $D$ supplementation and cardiovascular disease risks in more than 83000 individuals in 21 randomized clinical trials: a meta-analysis. JAMA Cardiol. 2019;19.

\section{Publisher's Note}

Springer Nature remains neutral with regard to jurisdictional claims in published maps and institutional affiliations.

Ready to submit your research? Choose BMC and benefit from:

- fast, convenient online submission

- thorough peer review by experienced researchers in your field

- rapid publication on acceptance

- support for research data, including large and complex data types

- gold Open Access which fosters wider collaboration and increased citations

- maximum visibility for your research: over $100 \mathrm{M}$ website views per year

At $\mathrm{BMC}$, research is always in progress.

Learn more biomedcentral.com/submissions 